\title{
Influence of the Loading Condition on Single Grain Crushing in DEM Simulation
}

\author{
Majid Movahedi Rad ${ }^{1 *}$, Saeed Safikhani², Erich Bauer ${ }^{2}$ \\ 1 Department of Structural and Geotechnical Engineering, Széchenyi István University, Egyetem tér 1, 9026 Győr, Hungary \\ 2 Institute of Applied Mechanics, Graz University of Technology, Technikerstrasse 4/II, 8010 Graz, Austria \\ * Corresponding author, e-mail: majidmr@sze.hu
}

Received: 12 June 2019, Accepted: 25 October 2019, Published online: 27 November 2019

\begin{abstract}
Grain crushing is of essential importance for understanding the mechanical behavior of granular materials such as sand, gravel or broken rock under higher pressures. In order to investigate the breakage mechanism of a single grain under different loading conditions, numerical simulations are carried out using DEM. Two different types of boundary conditions are considered to apply displacement-controlled load: loading using platens and loading by uncrushable macro-grains. A 2D crushable macro-grain is built up from a large number of micro-grains which are connected with respect to breakable parallel-bond properties. The response of the crushable macro-grain for different coordination numbers and location of the contact points is discussed. The numerical results show that the type of loading condition can influence the loading capacity and fragmentation patterns of the crushable macro-grain.
\end{abstract} Keywords

grain crushing, DEM, micro contact model, loading condition, fragmentation patterns

\section{Introduction}

The strength and breakage mechanisms of grains are of great importance for the mechanical response of granular materials under higher stress levels. Experiments show that grain crushing of a grain assembly under compression is dependent to a great extent, e.g. on the mineral composition, local defects of the micro-structures, the grain shape and grain size, the state of weathering, the grain size distribution, the initial packing density and the micro-mechanical parameters of the granular material [1-3]. Grain crushing causes a change of the grain size distribution, the grain shape, the critical void ratio and the limit void ratios $[4,5]$. The fragmentation patterns of each individual grain are also influenced by the coordination number and location of the contact points [6]. The investigation of such factors of influence in laboratory experiments is difficult and usually limited to macroscopic considerations. Numerical simulations using the discrete element method (DEM) offer the opportunity for gaining a deeper understanding of the grain crushing mechanism under different loading conditions.

For DEM simulation of crushable grains, the so-called replacement method and the bonded agglomerates method are two common concepts proposed in the literature. In the replacement method, when a grain failure criterion is met, the original grain is replaced by a predefined number of smaller grains $[7,8]$. The fitting of the volume with the smaller grains follows a predefined rule. A main critical aspect in this method is the fact that the replacement of the corresponding grain by smaller grains is either characterized by loss of solid mass, e.g. [9], or change of the equilibrium state because of an additional local pressure, which appears when the replaced grains do not fit precisely into the space of the corresponding grain before crushing [7]. In the agglomeration method, the crushable macro-grain is built up from a large number of micro-grains, which are connected by breakable bonds [10-16]. When grain fragmentation takes place, the resulting broken parts can show different shapes depending on the individual loading condition. The failure criterion between individual micro-grains is checked, using the assumed strength criterion of the bonds. In this method the refined simulation of the process of grain crushing is only limited by the maximum number of the micro-grains which can be taken into account depending on the capacity of the computer used. For instance, Bolton et al. [10] used only 378 crushable grains, consisting of less than 50 micro-grains each. 
The bonded agglomerates method is also used in this study. In a forthcoming paper, for oedometer simulations, the combination of two methods (the replacement method and the bonded agglomerates method) is aimed to use. However, when we study on accurate model the understanding of the fragmentation patterns and crushing of agglomerates in a single grain is an important requirement. For this reason, in this paper, the behavior of macro-single grain crushing tests under different boundary conditions and loading cases are numerically investigated using the discrete element method.

The objective of this paper is to simulate the effect of the loading condition on the loading capacity and grain crushing pattern of a single $2 \mathrm{D}$ crushable macro-grain under compression. The influence of the loading condition is investigated for two different boundary types: loading with platens and loading via uncrushable macro-grains. The DEM simulations are carried out using the Itasca Particle Flow Code. This paper is organized as follows: In the Section 2 the macro-grain generation and parallel-bond contact properties are discussed. In Section 3 the loading conditions and different boundary types are introduced. In Section 4 numerical results in the form of load displacement diagrams and grain fragmentation patterns are discussed. Conclusions are given in Section 5.

\section{Crushable macro-grain generation}

The generation of the crushable macro-grain consists of the following steps: the macro-grain is generated by a random distribution of micro-grains filling the domain defined by the radius of the macro-grain. It can be noted that the random distribution of micro-grains takes into account a certain inhomogeneous micro-structure of the macro-grain. The finalized shape of the unsmooth surface of the macro-grain depends on the ratio of the diameter of micro-grain to the macro-grain and of the location of the micro-grains along the boundary of the macro-grain. The diameter of the micro-grains is chosen such that the resulting macro-grain should contain enough micro-grains to simulate the fragmentation process adequately. In particular, the crushable macro-grain with a diameter of $5.2 \mathrm{~cm}$ is filled with 524 micro-grains with a diameter of $0.2 \mathrm{~cm}$ and density of $2.65 \mathrm{~g} / \mathrm{cm}^{3}$. In $2 \mathrm{D}$ simulation the thickness of micro-grain disks is unit, herein it is $1 \mathrm{~cm}$. Two types of contacts are considered in our DEM model. The first contact is unbonded contact which is described by the linear contact model. This is proper for contacts between macrograins, and between micro-grains along cracking shores.
The second contact is bonded contact which is defined between micro-grains and described by the so-called parallel bond properties. A parallel bond defines the cementation between the micro-grains. In a bonded contact, the parallel bond provides additional stiffness and strength to the contact. The parallel bond can be considered as a circular, finite-sized contact surface transmitting normal and tangential forces, corresponding to a cross-section in a beam submitted to normal and tangential forces and bending and torsional moments. The contact properties assumed in this paper are summarized in Table 1.

The uncrushable macro-grains also have a circular shape with a diameter of $2 \mathrm{~cm}$ and generated using 150 micro-grains with the diameter of $0.2 \mathrm{~cm}$. The normal and shear strength for the contact properties of the uncrushable macro-grains are considered as sufficiently high to prevent any bond breakage during loading. The normal and shear stiffness for the uncrushable macro-grains are the same as those for crushable macro-grains.

\section{Single macro-grain crushing test}

The breakage of bonds in a crushable macro-grain is investigated for different coordination numbers and the corresponding location of the contact points. Two different contact models are considered: grain-platen contact model (GPM) and grain-grain contact model (GGM). In the case of GPM the crushable macro-grain is loaded using smooth rigid platens. For the GGM, the load is applied to the crushable macro-grain using smaller uncrushable macro-grains, which simulate the situation in a grain assembly more realistically. These two models are outlined in more detail in the following.

\subsection{Grain-platen contact model (GPM)}

In order to investigate the effect of number and location of the smooth and rigid loading platens on the load-displacement behavior of the crushable macro-grain, three different boundary conditions are considered (Fig. 1). In case GPM-I the crushable macro grain is vertically compressed

Table 1 Contact properties

\begin{tabular}{lc}
\hline \multicolumn{2}{c}{ Unbonded contact (linear contact) } \\
\hline Normal and shear stiffness [N/cm] & 30000 \\
Friction coefficient & 0.55 \\
\multicolumn{1}{c}{ Bonded contact (parallel-bond contact) } & \\
Normal and shear stiffness [N/cm] & 600000 \\
Normal and shear strength [N/cm $\left.{ }^{2}\right]$ & 3000 \\
Ratio of bond radius to micro-grain radius & 0.5 \\
\hline
\end{tabular}


between two parallel platens. In case GPM-II three platens are in contact with the crushable macro-grain where the top platen is horizontal and the other two platens make $45^{\circ}$ with the horizontal axis. The two inclined platens are assumed to be fixed in space and the vertical displacement of the top platen is prescribed (Fig. 1b). In case GPM-III (Fig. 1c), four perpendicular platens are acting on the crushable macro-grain, which moves toward the original center of the crushable macro-grain.

\subsection{Grain-grain contact model (GGM)}

In order to investigate the contact properties in a grain assembly more realistically, uncrushable macro-grains are placed around the crushable macro-grain. The load is transmitted to these uncrushable macro-grains using rigid platens with smooth surfaces. Fig. 2 illustrates the different boundary conditions which are investigated. Cases GGM-I and GGM-II are similar to the cases GPM-I and GPM-II, respectively, however, the uncrushable macro- grain located at the top is fixed only in the horizontal direction, while the displacement is prescribed in the vertical direction. The other uncrushable macro-grains are fixed for both the horizontal and the vertical directions (Fig. 2a, b). In case GGM-III the crushable macro-grain is loaded by four uncrushable macro-grains, which make $90^{\circ}$ angles with each other and all of them are moved toward the center of the crushable macro-grain (Fig. 2c).

\section{Results of the numerical simulation 4.1 Case GPM-I}

The fragmentation pattern shows a main crack in the middle of the crushable macro-grain, but the fragmentation is not perfectly symmetrical (Fig. 3a). The activated force first increases with increasing of the prescribed vertical displacement and it suddenly drops immediately after the peak point (Fig. 3b). The peak point is reached at vertical deformation of $2.8 \mathrm{~mm}$ and a vertical contact load of $6.2 \mathrm{kN}$.

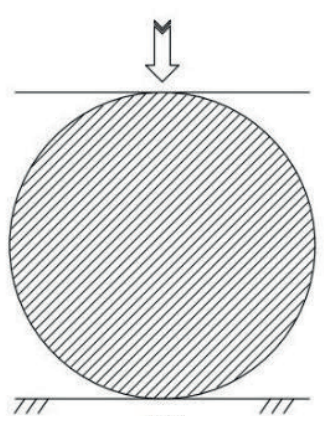

(a)

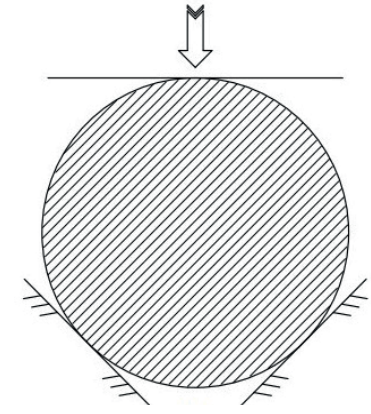

(b)

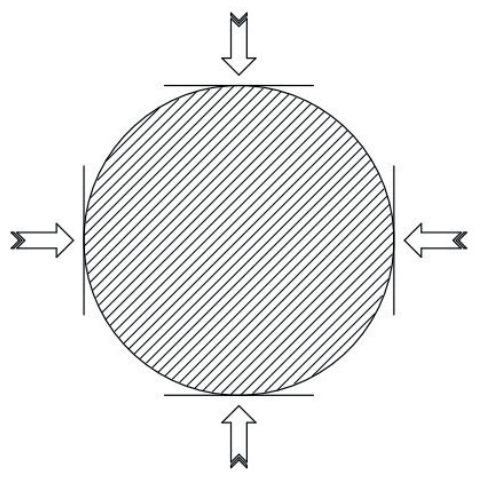

(c)

Fig. 1 Grain-platen contact models: (a) case GPM-I has two parallel contacts; (b) case GPM-II has three contacts; (c) case GPM-III has four contacts

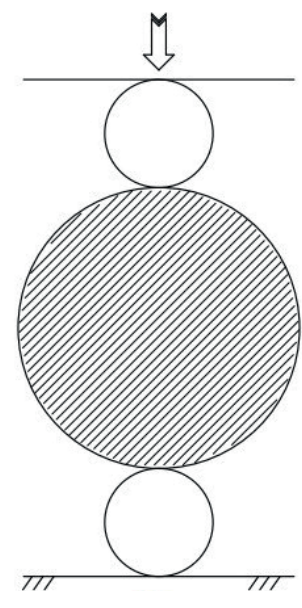

(a)

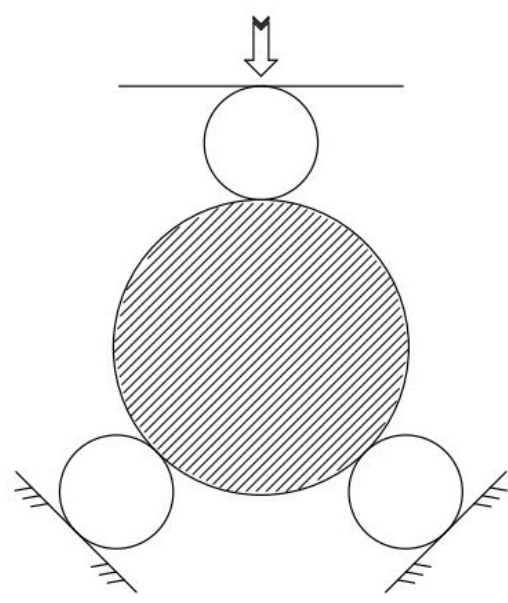

(b)

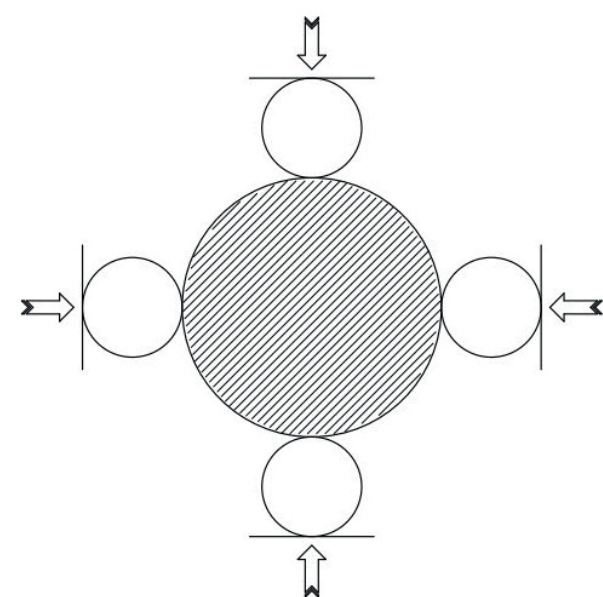

(c)

Fig. 2 Grain-grain contact models: (a) case GGM-I has two orientation boundaries; (b) case GGM-II has three orientation boundaries;

(c) case GGM-III has four orientation boundaries 


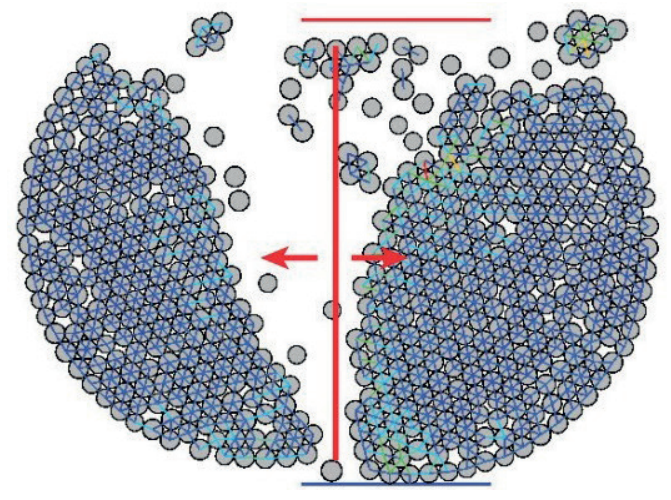

(a)

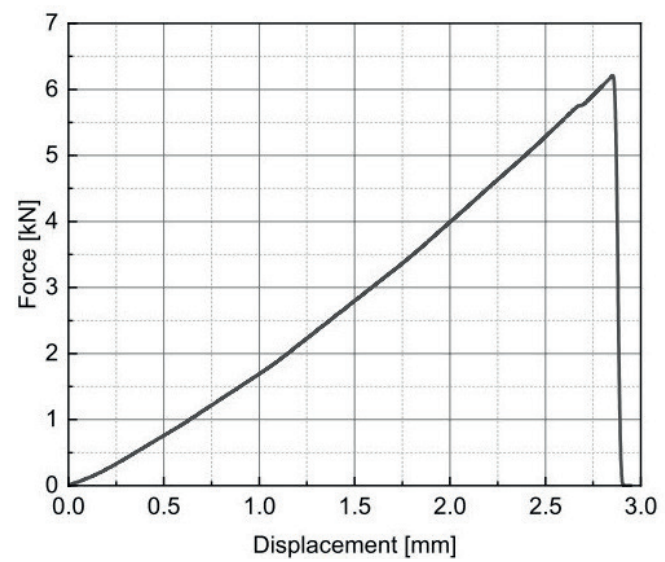

(b)

Fig. 3 Case GPM-I: (a) diametric fragmentation patterns; (b) force-displacement diagram

\subsection{Case GPM-II}

In this case the breakage is neither diametric nor sudden drop (Fig. 4a, b). When the applied vertical displacement reaches a value of $2.25 \mathrm{~mm}$, the maximum vertical force is $4.7 \mathrm{kN}$ and it is much smaller than in case GPM-I. In this state, some bonds are already broken. After the peak point, the vertical load first decreases slightly and then increases to reach a further peak at about $2.5 \mathrm{~mm}$. A continued vertical displacement leads to a reduction of the vertical load. The macro-grain crushes into three main fragments, but the shapes of the broken pieces differ significantly. This non-symmetric crushing could be a result of the random distribution of location of micro-grains within the macro-grain. As can be concluded from Fig. 4a, the width of the loading platen also has a great influence on the pre-peak and postpeak behavior of the macro-grain. Numerical simulations show, that for pre-peak states, the number of particles that are in contact with the loading platen is influenced by its width. Furthermore a wider platen can keep some broken parts of the macro-grain in place for the post-peak state. This will lead to a higher loading capacity in post-peak states.

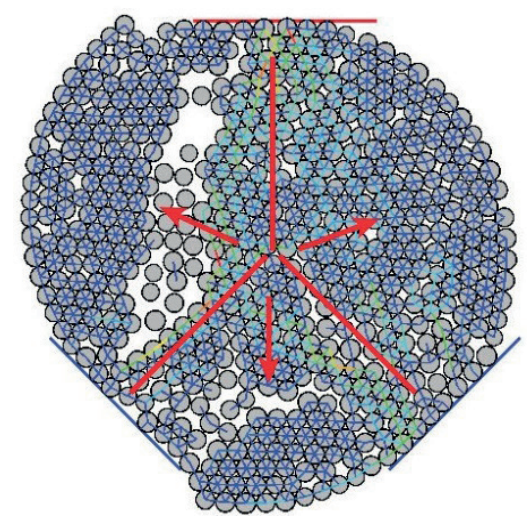

(a)

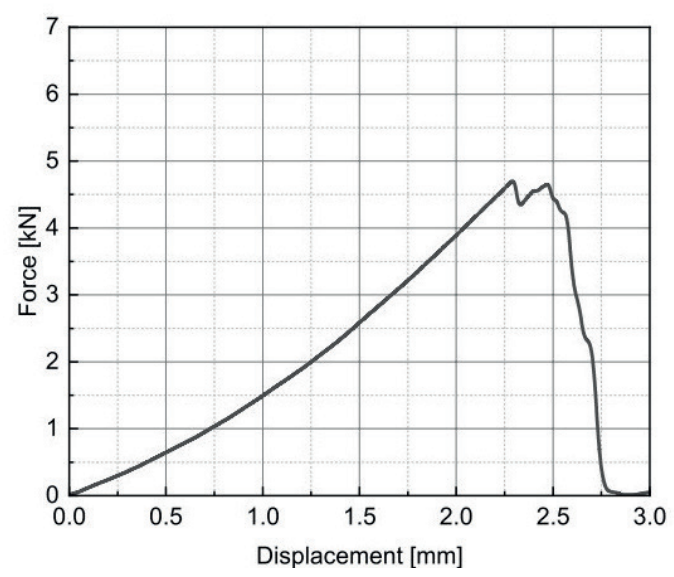

(b)

Fig. 4 Case GPM-II: (a) fragmentation patterns;

(b) force-displacement diagram

\subsection{Case GPM-III}

The force-displacement diagram for case GPM-III shows a more complex post-peak behavior, which indicates the evolution of several major failure zones. The main peak point at $6 \mathrm{kN}$ vertical load corresponds to a vertical displacement of $1.4 \mathrm{~mm}$ of the top platen. The change of the vertical displacement shown in Fig. $5 b$ is the half of the total, since the bottom platen simultaneously moves upwards. It should be noted that for the case GPM-III, the width of the platens has an influence on pre-peak and postpeak behavior of the macro-grain.

A comparison of the loading capacities of cases GPM-I, GPM-II and GPM-III shows a higher capacity of case GPM-I. The vertical displacement of the crushable macro-grain until the reaction force falls to zero is higher in the case GPM-III compared to the other cases.

\subsection{Case GGM-I}

Fig. 6 shows the fragmentation patterns and force-displacement diagram of case GGM-I. Similar to the GPM-I the fragmentation patterns show an almost diametric crack 


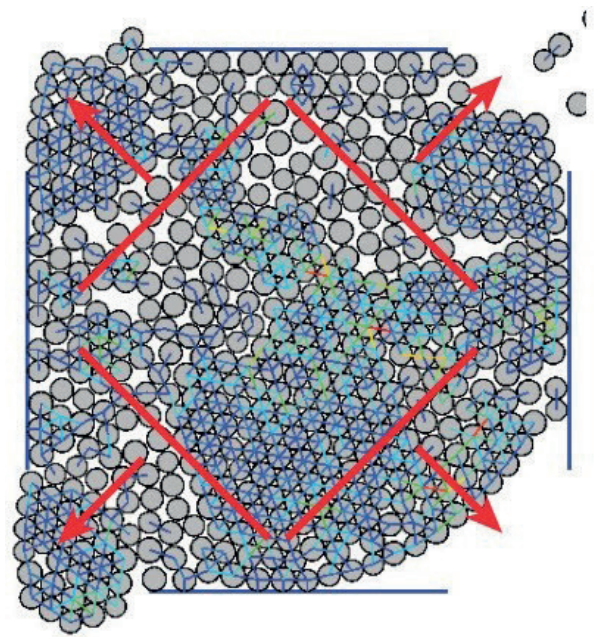

(a)

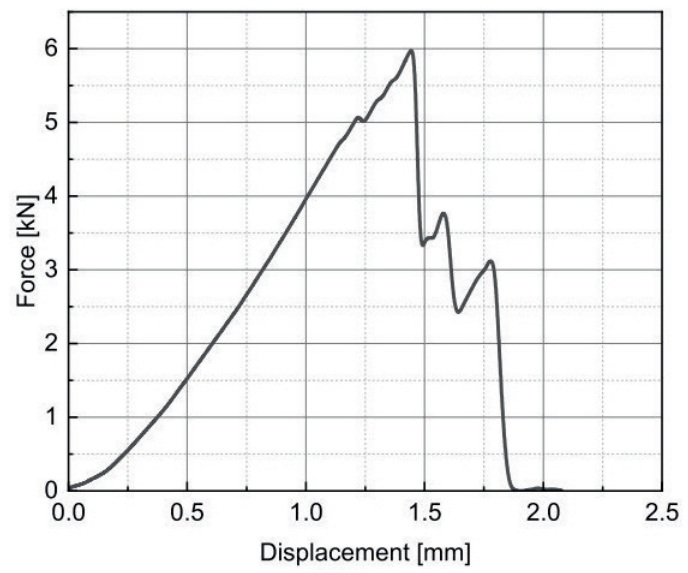

(b)

Fig. 5 Case GPM-III: (a) fragmentation patterns; (b) force-displacement diagram

inside the particle (Fig. 6a) and the breakage mechanism is almost a sudden drop (Fig. 6b). The diametric breakage takes place at $5.1 \mathrm{kN}$ load and $5.0 \mathrm{~mm}$ vertical displacement. As the shape of surface of the grains is irregular it is possible to have more than one contact between crushable and uncrushable macro-grain.

A greater number of contacts leads to an enlarged contact surface and this can increase during loading. The loading capacity of crushable macro-grain in case GGM-I is less than in the GPM-I case and a result of the less enlarged contact surface. The smaller contact surface corresponds to a smaller number of micro-grains of the uncrushable macro-grain, which are in contact with micro-grains of the crushable macro-grain. The vertical displacement in case GGM-I is higher than in case GPM-I, which can be a result of higher deformability of uncrushable macro-grain compared to the stiff loading platens in GPM cases.

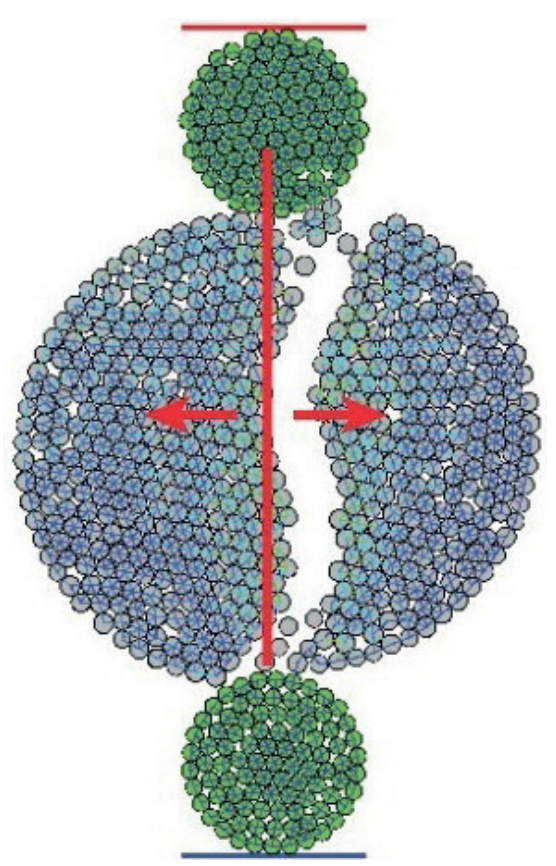

(a)

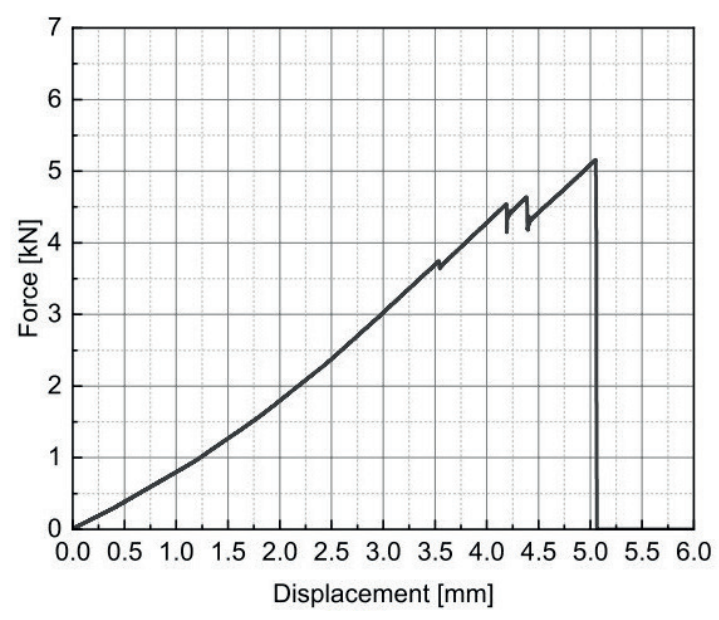

(b)

Fig. 6 Case GGM-I: (a) fragmentation patterns; (b) force-displacement diagram

\subsection{Case GGM-II}

According to Fig. 7a the fragmentation patterns in this case consist of three main parts. In contrast to the case GPM-II, in the case GGM-II the breakage mechanism is a completely sudden drop immediately after the peak (Fig. 7b). During loading, several minor drops are visible and these are caused by local breakage or a rotation of the crushable macro-grain. The vertical displacement of case GGM-II is higher than for case GPM-II which is related to the deformability of the uncrushable macro-grain located at the top. The vertical displacement is higher than in case GGM-I because of the higher number of contact points with the uncrushable macro-grains. 


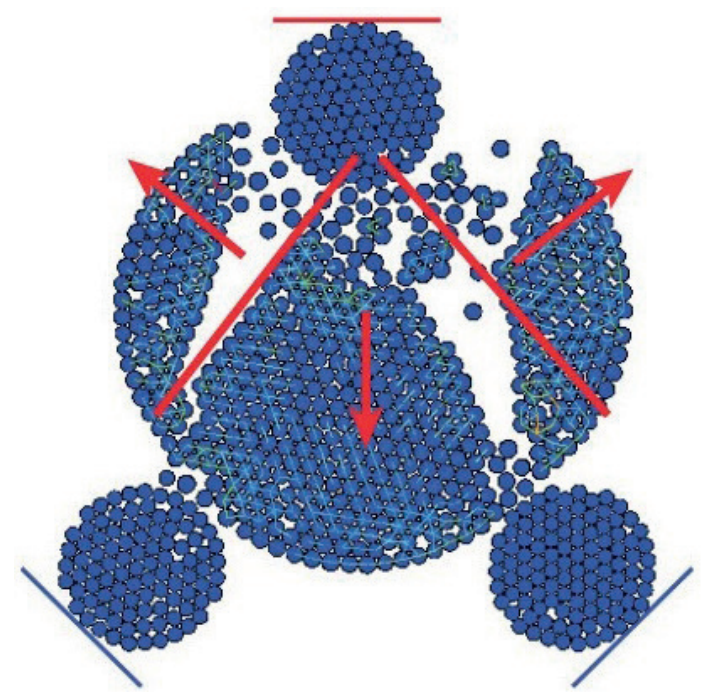

(a)

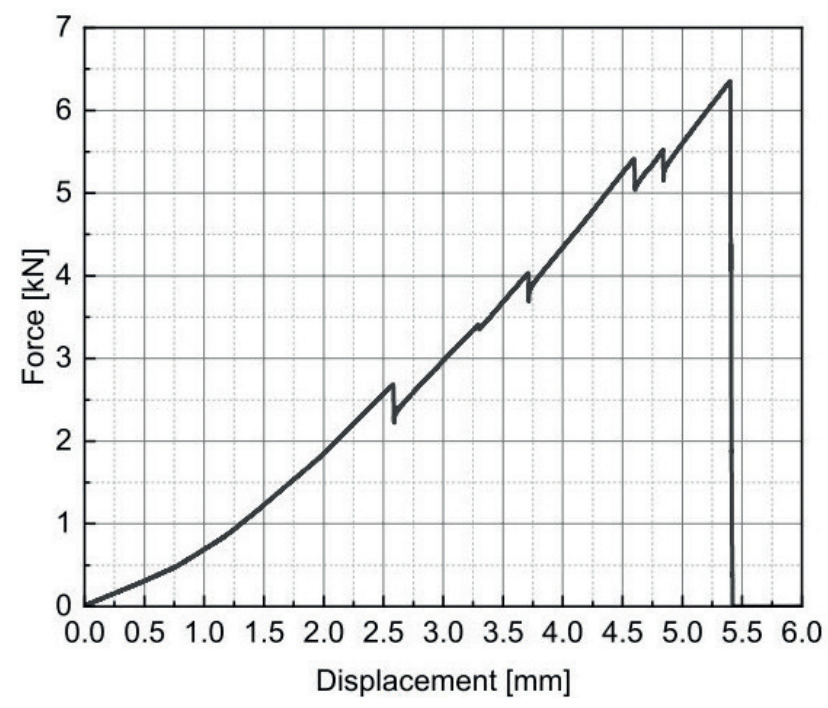

(b)

Fig. 7 Case GGM-II: (a) fragmentation patterns; (b) load-displacement diagram

\subsection{Case GGM-III}

The fragmentation patterns of case CGM-III can be divided into 5 different main parts with different sizes and shapes (Fig. 8a). The peak load is $6.2 \mathrm{kN}$ and is reached after a vertical displacement of about $3.6 \mathrm{~mm}$. immediately after the peak the breakage mechanism has a completely sudden drop (Fig. 8b). It should be noted that the bottom platen is also moving upward and the vertical displacement in Fig. 8b is only the corresponding value for the top platen. This fact leads to a higher deformability until the maximum load is reached compared to the cases GGM-I and GGM-II. The maximum loading capacity of the case GGM-III is almost the same as in case GGM-II, but higher than in case GGM-I.

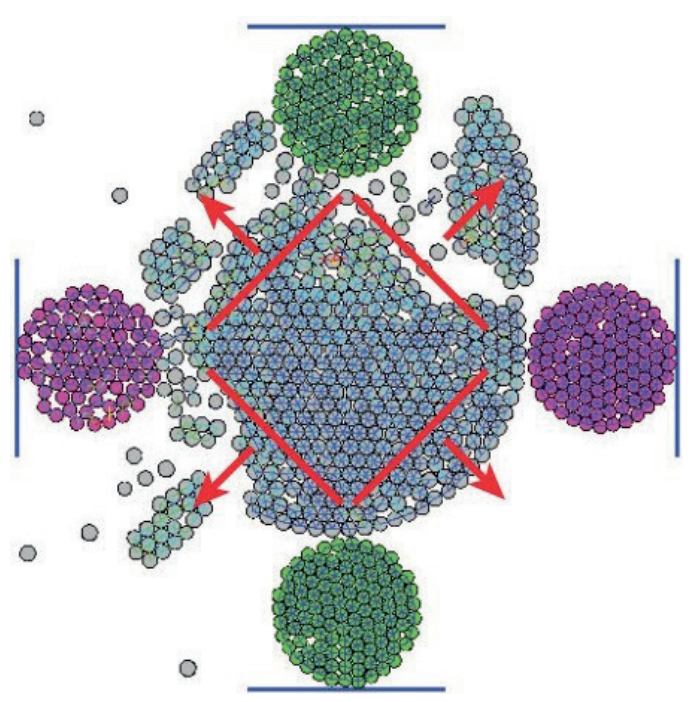

(a)

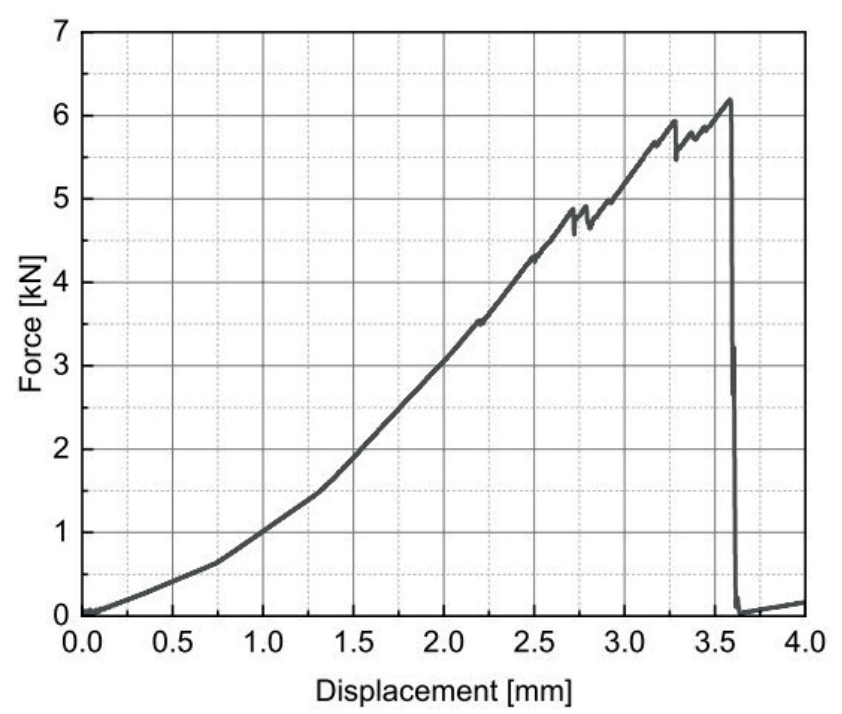

(b)

Fig. 8 Case GGM-III: (a) fragmentation patterns; (b) load-displacement diagram

\section{Conclusions}

In this paper, the behavior of single macro-grain crushing tests under different boundary conditions is numerically investigated using the discrete element method. In order to investigate the effect of different loading conditions two different contact models are defined: grainplaten and grain-grain contact models. Numerical simulations are carried out with different number and location of contact points. The results show that the boundary condition can have a strong influence on the loading capacity and the fragmentation patterns. Essential results are summarized in Table 2. For the grain-platen contact models the loading capacity of the crushable macro-grain in the four platen loading case is almost the same as for the 
Table 2 Simulation results for different contact models

\begin{tabular}{lccc}
\hline Contact & $\begin{array}{c}\text { Maximum } \\
\text { force }(\mathrm{kN})\end{array}$ & $\begin{array}{c}\text { Displacement at } \\
\text { peak point }(\mathrm{mm})\end{array}$ & $\begin{array}{c}\text { Number of } \\
\text { fragments }\end{array}$ \\
\hline GPM-I & 6.2 & 2.8 & 2 \\
GPM-II & 4.7 & 2.25 & 3 \\
GPM-III & 6.0 & 1.4 & several major parts \\
GGM-I & 5.1 & 5.0 & 2 \\
GGM-II & 6.3 & 5.4 & 3 \\
GGM-III & 6.2 & 3.6 & 5 \\
\hline
\end{tabular}

two-platen loading case, but breakage occurs as the multistep drops. On the other hand, in the case of the graingrain contact model the loading capacity of the four-platen loading case and the three-platen loading case is almost

\section{References}

[1] Ovalle, C., Frossard, E., Dano, C., Hu, W., Maiolino, S., Hicher, P.-Y. "The effect of size on the strength of coarse rock aggregates and large rockfill samples through experimental data", Acta Mechanica, 225(8), pp. 2199-2216, 2014

https://doi.org/10.1007/s00707-014-1127-z

[2] Zhao, B., Wang, J., Coop, M. R., Viggiani, G., Jiang, M. "An investigation of single sand particle fracture using X-ray micro-tomography", Géotechnique, 65(8), pp. 625-641, 2015.

https://doi.org/10.1680/geot.4.P.157

[3] Tamás, K., Földesi, B., Rádics, J. P., Jóri, I. J., Fenyvesi, L. "A Simulation Model for Determining the Mechanical Properties of Rapeseed using the Discrete Element Method", Periodica Polytechnica Civil Engineering, 59(4), pp. 575-582, 2015. https://doi.org/10.3311/PPci.8173

[4] Luzzani, L., Coop, M. R. "On the relationship between particle breakage and the critical state of sand", Soils and Foundation, 42(2), pp. 71-82, 2002.

https://doi.org/10.3208/sandf.42.2 71

[5] Sadrekarimi, A., Olson, S. M. "Critical state friction angle of sands", Géotechnique, 61(9), pp. 771-783, 2011.

https://doi.org/10.1680/geot.9.P.090

[6] Salami, Y., Dano, C., Hicher, P.-Y. "An experimental study on the influence of the coordination number on grain crushing", European Journal of Environmental and Civil Engineering, 23(3), pp. 432448, 2019.

https://doi.org/10.1080/19648189.2017.1285251

[7] McDowell, G. R., de Bono, J. P. "On the micro mechanics of onedimensional normal compression", Géotechniqe, 63(11), pp. 895908, 2013.

https://doi.org/10.1680/geot.12.P.041

[8] Lobo-Guerrero, S., Vallejo, L. E. "Discrete Element Method Analysis of Railtrack Ballast Degradation during Cyclic Loading", Granular Matter, 8(3-4), pp. 195-204, 2006. https://doi.org/10.1007/s10035-006-0006-2 the same. Some minor drops in the reaction force are visible in GGM cases, while in the GPM cases the pre-peak behavior maintains an almost continuous course. After the maximum load is reached, a sudden drop of the reaction force can be detected in all GGM cases. The vertical displacements of GGM are higher than GPM which can be explained by the deformability of the uncrushable macro-grains.

\section{Acknowledgement}

The present study was supported by the Hungarian National Research, Development and Innovation Office (TÉT-AT-2017-00007) and by the Austrian Ministry of Science (WTZ Project: HU 01/2017).

[9] Marketos, G., Bolton, M. D. "Compaction bands simulated in Discrete Element Models", Journal of Structural Geology, 31(5), pp. 479-490, 2009 https://doi.org/10.1016/j.jsg.2009.03.002

[10] Bolton, M. D., Nakata, Y., Cheng, Y. P. "Micro- and macro-mechanical behaviour of DEM crushable materials", Géotechnique, 58(6), pp. 471-480, 2008 https://doi.org/10.1680/geot.2008.58.6.471

[11] Whittles, D. N., Kingman, S., Lowndes, I., Jackson, K. "Laboratory and numerical investigation into the characteristics of rock fragmentation", Minerals Engineering, 19(14), pp. 1418-1429, 2006. https://doi.org/10.1016/j.mineng.2006.02.004

[12] Refahi, A., Mohandesi, J. A., Rezai, B. "Discrete element modeling for predicting breakage behavior and fracture energy of a single particle in a jaw crusher", International Journal of Mineral Processing, 94(1-2), pp. 83-91, 2010. https://doi.org/10.1016/j.minpro.2009.12.002

[13] McDowell, G. R., Harireche, O. "Discrete element modelling of soil particle fracture", Géotechnique, 52(2), pp. 131-135, 2002. https://doi.org/10.1680/geot.2002.52.2.131

[14] McDowell, G. R., Harireche, O. "Discrete element modelling of yielding and normal compression of sand", Géotechnique, 52(4), pp. 299-304, 2002 https://doi.org/10.1680/geot.2002.52.4.299

[15] Cheng, Y. P., Nakata, Y., Bolton, M. D. "Discrete element simulation of crushable soil", Géotechnique, 53(7), pp. 633-641, 2003. https://doi.org/10.1680/geot.2003.53.7.633

[16] Zheng, W., Tannant, D. D. "Grain breakage criteria for discrete element models of sand crushing under one-dimensional compression", Computers and Geotechnics, 95, pp. 231-239, 2018. https://doi.org/10.1016/j.compgeo.2017.10.004 